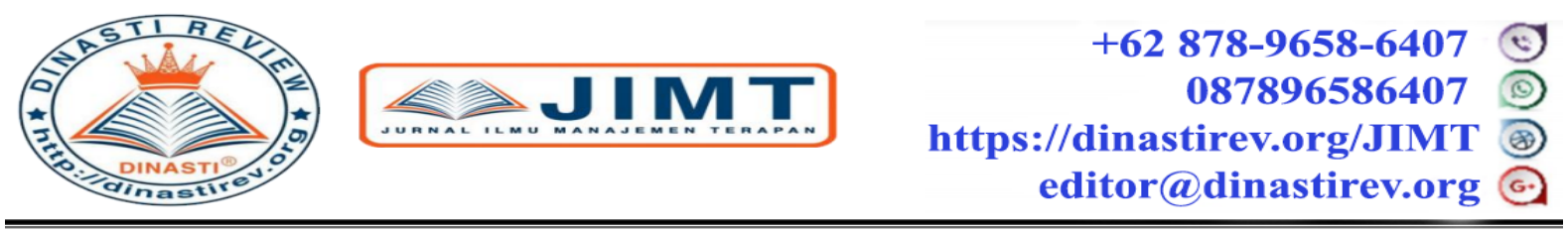

\title{
ANALISIS STRATEGI PEMASARAN DENGAN MENGGUNAKAN METODE QUANTITATIVE STRATEGIC PLANNING MATRIX (QSPM) PADA USAHA KECIL MENENGAH (UKM) (Studi Kasus pada Roman Indah Ukm di Padang)
}

\section{Marta Widian Sari}

Universitas Putra Indonesia "YPTK" Padang

\begin{tabular}{|c|c|}
\hline $\begin{array}{c}\text { ARTICLE INFORMATION } \\
\text { Received: 02/09/2019 } \\
\text { Revised: 11/09/2019 } \\
\text { Issued: 20/09/2019 } \\
\text { (filled in by Editor) } \\
\\
\text { Corresponding Author: } \\
\text { Marta Widian Sari } \\
\text { E-mail: martawidiansari@ upiyptk.ac.id } \\
\end{array}$ & $\begin{array}{l}\text { Abstrak: Roman Indah UKM Padang merupakan pabrik } \\
\text { tas yang tergolong Usaha Kecil Menengah (UKM) yang } \\
\text { berada di Jl. Aur Duri Padang, perusahaan ini memenuhi } \\
\text { permintaan pembuatan tas untuk perlengkapan kegiatan } \\
\text { seperti; kogres, seminar, wisuda, diklat, dan kontigen. } \\
\text { Metode yang digunakan adalah SWOT dan QSPM. Data } \\
\text { yang digunakan adalah data primer dan data sekunder. } \\
\text { Berdasarkan dari hasil pengolahan data diperoleh nilai } \\
\text { dari matriks IFE sebesar 3,187981859 sedangkan } \\
\text { matriks EFE sebesar 3,141693291. Kemudian hasil yang } \\
\text { diperoleh pada matriks IE yaitu menempatkan } \\
\text { perusahaan berada pada se I yang disebut strategi } \\
\text { tumbuh dan kembangkan. Pada posisi tersebut, } \\
\text { perusahaan melakukan strategi penetrasi pasar, } \\
\text { pengembangan pasar, dan pengembangan produk. } \\
\text { Kemudian hasil yang diperoleh pada matriks QSPM, } \\
\text { alternatif strategi yang paling menarik dan diprioritaskan } \\
\text { untuk dilakukan oleh perusahaan yaitu Menerima } \\
\text { mahasiswa dan murid SMK magang atau PKL untuk } \\
\text { memperoleh tenaga kerja yang terampil, dengan nilai } \\
\text { TAS sebesar 0,6802. } \\
\text { Kata Kunci: Matriks SWOT, Matriks QSPM,Strategi } \\
\text { Pemasaran. }\end{array}$ \\
\hline
\end{tabular}

\section{PENDAHULUAN}

Perkembangan perdagangan global dan kemajuan teknologi bisa berdampak pada persaingan dalam menembus pasar baik skala tingkat nasional maupun tingkat internasional. Memasuki era globalisasi sekarang ini peranan kegiatan perdagangan internasional sangat penting. Perdagangan internasional sangat mempengaruhi perekonomian suatu negara, karena dalam perdagangan internasional semua negara bersaing di pasar internasional. Maka, dengan adanya kondisi tersebut para pelaku usaha dituntut untuk mengeluarkan produkproduk berkualitas yang sesuai dengan kebutuhan pasar nasional maupun internasional (Nugroho, 2016).

Perkembangan UKM di indonesia memang cukup menjanjikan. Oleh sebab itu, para 
pengusaha kecil dan menengah harus mampu meningkatkan ketajaman visi bisnis mereka, mengingat persaingan bisnis global semakin ketat. Persaingan yang semakin ketat ini, akan berdampak pada kinerja suatu UKM. Keadaan ini tidak terkecualiakan akan dihadapi oleh UKM yang bergerak pada pembuatan tas. Roman Indah UKM merupakan salah satu UKM yang berada di Kota Padang Provinsi Sumatera Barat. Perusahaan ini memproduksi tas yang berlokasi di jl. Aur duri indah raya, Padang Timur, Sumatera Barat. Dalam menjalankan usahanya Roman Indah UKM banayak mendapati permasalahan yang harus dihadapi, yaitu masalah internal maupun masalah eksternal yang harus diantisipasi dan diatasi oleh UKM tersebut. Beberapa faktor internal yang mempengaruhi salah satunya adalah belum adanya perluasan area penjualan dari pihak perusahaan dan faktor internal lainya adalah tidak stabilnya pendapatan Roman Indah Padang di setiap bulannya, sementara itu salah satu faktor eksternal yang mempengaruhi adalah adanya pesaing yang memproduksi produk tas sejenis yang berada tidak jauh dari lokasi Roman Indah Padang yaitu Sentra Kerajinan Tas dan Konveksi Adespuma oleh karena itu diperlukan strategi pemasaran yang tepat agar dapat mengoptimalkan kemampuan perusahaan dalam menjalankan usahanya sehingga mampu mampu berkembang dan bersaing dengan perusahaan sejenis.

Permasalahan yang di hadapi oleh Roman Indah dapat di selesaikan dengan menggunakan metode (QSPM) karena metode tersebut lebih terfokus pada perencanaan strategi perusahaan dan dapan pula digunakan untuk menentukan urutan prioritas strategi pemasaran yang di perlukan untuk perluasan pasar. Quantitative Strategic Planning Matrix (QSPM) merupakan alat ukur terakhir yang digunakan dalam penelitian untuk melakukan evaluasi pilihan strategi alternatif secara objektif berdasarkan tahap-tahap yang telah diidentifikasi sebelumnya (Zulkarnaen dan Sutopo, 2013).

Berdasarkan latar belakang di atas, maka peneliti tertarik untuk melakukan penelitian dengan judul "Analisis Strategi Pemasaran Dengan Menggunakan Metode Quantitative Strategic Planning Matrix (QSPM) (Studi Kasus Pada Roman Indah UKM di Padang).

\section{KAJIAN PUSTAKA}

\section{Pemasaran}

Menurut Djaslim S. dalam Abdurrahman (2015 : 2) Pemasaran adalah suatu sistem total dari kegiatan bisnis yang dirancang untuk merencanakan, menentukan harga, promosi, mendistribusikan barang-barang yang dapat memuaskan keinginan dan memcapai pasar sasaran serta tujuan perusahaan." Dalam pengertian modern dan globalisasi saat ini, defenisi pemasaran lebih luas lagi, di mana para pemasar sudah lebih berorientasi pada pelanggan , pada kepuasan pelanggan dan kesetiaan pelanggan terhadap produk dan merek.

Menurut Aarker (2013 : 13) Sebuah strategi yang dirancang untuk membantu manajemen menciptakan, mengubah, dan mempertahankan sebuah strategi bisnis dan untuk menciptakan visi strategis. Sebuah visi strategis akan memberikan arahan dan tujuan yang sifatnya menginspirasi orang- orang yang ada dalam organisasi dengan memberikan sebuah tujuan yang membanggakan.

Aarker juga mengemukakan bahwa pengembangan strategi bisnis yang benar merupakan sasaran yang mendasar, tetapi hal tersebut bukanlah akhir dari cerita. Dikarenakan masih banyak hal-hal yang perlu dilakukan dalam mengembangkan strategi, diantaranya adalah dengan memastikan bahwa strategi tersebut tetap layak dengan keadaan 
pasar yang telah berubah terhadap peluang yang ada, memastikan bahwa organisasi mampu mengembangkan dan mempertahankan yang nantinya strategi tersebut dapat berhasil, dan menerapkan strategi dengan fokus sehingga tidak akan terjadi kegagalan.

\section{Matriks Internal Factor Evaluation (IFE) dan Matriks External Factor Evaluation (EFE)}

Matriks IFE digunakan untuk mengetahui faktor-faktor internal perusahaan berkaitan dengan kekuatan dan kelemahan yang dianggap penting. Data dan informasi aspek internal perusahaan dapat digali dari beberapa fungsional perusahaan, misalnya dari aspek manajemen, keuangan, SDM, pemasaran, sistem informasi, dan produksi.

Matriks EFE digunakan untuk mengevaluasi faktor-faktor eksternal perusahaan. Data eksternal dikumpulkan untuk menganalisis hal-hal menyangkut persoalan ekonomi, sosial, budaya, demografi, lingkungan, politik, pemerintahan, hukum, teknologi, persaingan di pasar industri di mana perusahaan berada, serta data eksternal relevan lainnya. Hal ini penting karena faktor eksternal berpengaruh secara langsung maupun tidak langsung terhadap perusahaan (Umar, 2002).

Menurut Rangkuti dalam Nugroho (2016) Matriks Internal-Eksternal (IE) ini dikembangkan dari model General Electric (GE). Parameter yang digunakan meliputi parameter kekuatan internal perusahaan dan pengaruh eksternal yang dihadapi. Tujuan penggunaan model ini adalah untuk memperoleh strategi bisnis di tingkat korporat atau divisi unit bisnis yang lebih detail.

\section{SWOT (Strength Weakness Opportunity Threat)}

Menurut Mary dan Coulter (2014) mendefenisikan analisis SWOT adalah suatu analisis organisasi dengan menggunakan kekuatan, kelemahan, kesempatan serta ancaman dari lingkungan. Sementara menurut Rangkuti (2014), analisis SWOT adalah identifikasi berbagai factor secara sistematis untuk merumuskan strategi perusahaan.

Analisa SWOT merupakan sebuah metode perencanaan strategis yang digunakan untuk mengevaluasi kekuatan, kelemahan, peluang, dan ancaman dalam suatu proyek atau suatu spekulasi bisnis. Proses ini melibatkan penetuan tujuan yang spesifik dari spekulasi bisnis atau proyek an mengidentifikasi faktor internal dan eksternal yang menukung dan yang tidak dalam mencapai tujuan tersebut.

\section{QSPM (Quantitative Strategic Planning Matrix)}

Menurut David dalam (Wijaya, 2013) QSPM (Quantitative Strategic Planning Matrix) merupakan sebuah strategi yang digunakan untuk mengevaluasi alternatif strategi secara obyektif berdasarkan faktor- faktor internal dan eksternal yang sebelumnya sudah diidentifikasi. Dalam hal ini, seorang pengusaha harus bisa menentukan strategi yang baik yang sesuai dengan kondisi internal dan eksternal perusahaan.

QSPM juga berguna sebagai penentuan strategi yang sudah diidentifikasi daya tarik relatifnya berdasarkan faktor-faktor internal dan eksternal perusahaan. QSPM juga mempunyai keistimewaan yang mana rangkaian strateginya dapat dilihat dan diamati secara berurutan berdasarkan hasil nilai TAS (Total Attractive Scores) serta keistimewaan yang lain 
berupa penyusun atau peneliti dapat memasukkan terobosan strategi berdasarkan faktor internal dan eksternal yang sesuai dalam proses pengambilan keputusan.

Di samping memiliki keistimewaan yang sudah diuraikan diatas, QSPM juga memiliki beberapa kelemahan yaitu dalam pengolahannya selalu membutuhkan penilaian dan asumsi yang mendasar, pemberian peringkat dan skor daya tarik berdasarkan pada keputusan penilaian yang diambil dari informasi yang objektif. Kelemahan yang lain yaitu hasil analisis ini akan menjadi baik dan bermanfaat apabila didasarkan pada informasi prasyarat dan dilakukan analisis pencocokan.

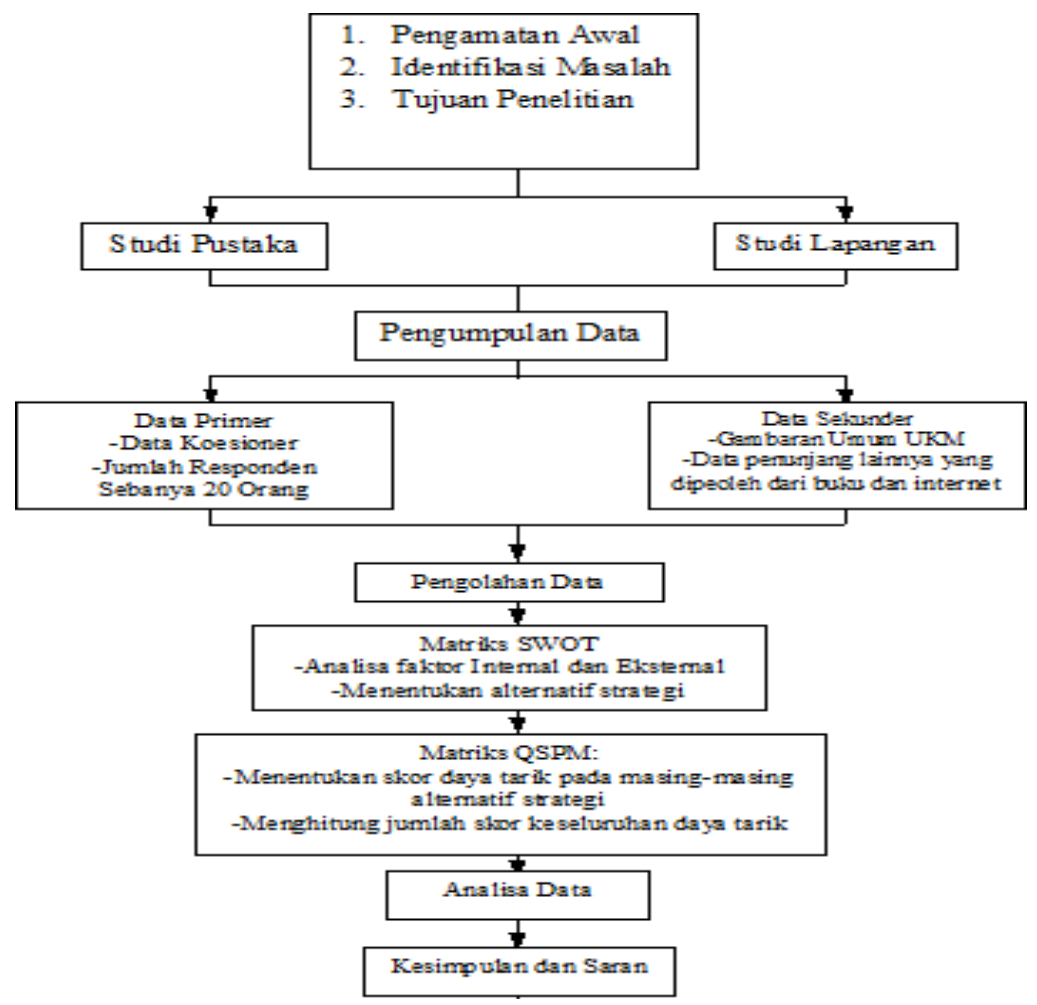

\section{Gambar 1. Kerangka Berpikir}

\section{METODE PENELITIAN}

Penelitian ini dilakukan pada perusahaan yang memproduksi produk-produk tas dengan cara langsung menuju obyek yang dituju, dan obyek penelitiannya adalah Roman Indah UKM dengan alamat di Jl. Aur Duri Indah Raya No. 5-9-11, Padang Timur, Sumatera Barat.

Dalam tahap penelitian terdapat metode-metode pengumpulan data diantaranya sebagai berikut:

1. Studi Lapangan (Observasi)

Metode yang dilakukan dengan cara pengamatan langsung pada objek yang diteliti.

Dalam penelitian ini, melakukan pengamatan untuk kevalidan data perusahaan.

2. Studi Pustaka

Pengumpulan data yang dilakukan dengan cara mencari dari berbagai sumber, misalnya referensi dari buku, jurnal dari penelitian sebelumnya yang terkait dengan jalannya penelitian yang akan dilakukan. 
3. Kuisioner

Pengumpulan data dengan cara melakukan kegiatan wawancara kepada pelaku usaha tersebut. Jumlah responden yang dipilih untuk pengisian kuisioner sebanyak 15 responden. Dalam hal ini pertimbangan yang dilakukan didasarkan pada responden tersebut erat kaitannya dalam pengambilan keputusan dan mengetahui informasi yang dibutuhkan. Kegiatan wawancara dan kuisioner ini dilakukan untuk mengidentifikasi faktor-faktor internal dan eksternal yang berpengaruh terhadap kinerja perusahaan.

4. Wawancara

Teknik pengambilan data di lapangan dengan cara melakukan tanya jawab secara langsung kepada pelaku industri yang ada di Roman Indah UKM .

5. Dokumentasi

Merupakan pengumpulan data dengan cara menggunakan gambar, video, dan dokumendokumen lainnya yang mendukung untuk dimasukkan dalam penelitian.

\section{HASIL DAN PEMBAHASAN}

\section{Responden Penelitian}

Tabel 1: Responden Kelompok Internal dan Eksternal

\begin{tabular}{|c|c|l|c|c|}
\hline No & Kelompok & \multicolumn{1}{|c|}{ Kategori } & Jumlah & Persentase (\%) \\
\hline 1 & Internal & Roman Indah Padang & 17 & 85 \\
\hline 2 & \multirow{2}{*}{ Eksternal } & Konsumen & 2 & 10 \\
\cline { 3 - 5 } & & Pesaing & 1 & 5 \\
\hline \multicolumn{2}{|c|}{ Total } & 20 & 100 \\
\hline
\end{tabular}

Pada tabel 1 dapat dilihat bahwa jumlah responden berdasarkan kelompok internal (Roman Indah Padang) sebanyak 17 responden dengan persentase 85\%, meliputi: karyawan. Kemudian untuk kelompok eksternal terdapat konsumen sebanyak 2 responden dengan persentase 10\%, meliputi Rika (Semen Padang Hospital) dan Diece (Perbarindo). Dan untuk kelompok eksternal lainnya terdapat pesaing sebanyak 1 perusahaan dengan persentase 5\%, meliputi Sentra Kerajinan Tas dan Konveksi Adespuma Padang.

\section{Identifikasi Kekuatan dan Kelemahan}

Tabel 2: Identifikasi Kekuatan dan Kelemahan Pada Roman Indah Padang

\begin{tabular}{|c|c|c|c|}
\hline $\begin{array}{l}\text { Faktor } \\
\text { Internal }\end{array}$ & Kekuatan & Faktor Internal & Kelemahan \\
\hline Manajemen & $\begin{array}{l}\text { Memiliki sistem manajemen } \\
\text { perusahaan yang baik }\end{array}$ & Manajemen & $\begin{array}{l}\text { Penggunaan Website } \\
\text { belum optimal }\end{array}$ \\
\hline & $\begin{array}{l}\text { Harga produk yang terjangkau oleh } \\
\text { konsumen }\end{array}$ & \multirow{3}{*}{ pemasaran } & $\begin{array}{l}\text { Wilayah pemasaran yang } \\
\text { kurang luas }\end{array}$ \\
\hline Pemasaran & Lokasi perusahaan yang stategis & & belum mempunyai \\
\hline \multirow[t]{3}{*}{ Keuangan } & Modal pribadi perusahaan & & $\begin{array}{l}\text { layanan penjuaran } \\
\text { melalui internet }\end{array}$ \\
\hline & $\begin{array}{l}\text { Produk yang di hasilkan sangat } \\
\text { berkualitas dan tahan lama }\end{array}$ & produksi & $\begin{array}{l}\text { Proses pembuatan tas } \\
\text { memakan waktu yang }\end{array}$ \\
\hline & & & cukup lama \\
\hline
\end{tabular}




\begin{tabular}{|c|l|}
\hline produksi & $\begin{array}{l}\text { Tas dapat dibuat berbagai model tas } \\
\text { sesui keinginan dan kebutuhan } \\
\text { konsumen }\end{array}$ \\
\hline & $\begin{array}{l}\text { Dikerjakan dengan } \\
\text { menggunakanmesin jahit modern }\end{array}$ \\
\hline
\end{tabular}

Desain produk yang mudah di tiru oleh pesaing perusahaan belum memiliki merek tas Pabrik tas yang kurang luas

Pada tabel 2 dapat dilihat bahwa identifikasi kekuatan dan kelemahan didapatkan dari hasil penyebaran kuisioner dan wawancara dari pihak internal yaitu Roman Indah Padang dan pihak eksternal yaitu konsumen dan pesaing. Setelah itu hasil kuisioner diidentifikasi berdasarkan faktor internal Identifikasi Peluang dan Ancaman.

\section{Identifikasi Peluang dan Ancaman}

Tabel 3: Identifikasi Peluang dan Ancaman Pada Roman Indah Padang

\begin{tabular}{|c|c|c|c|}
\hline No. & $\begin{array}{c}\text { Faktor } \\
\text { Eksternal }\end{array}$ & Peluang & Ancaman \\
\hline \multirow{4}{*}{1.} & \multirow{4}{*}{$\begin{array}{l}\text { Lingkungan } \\
\text { Makro }\end{array}$} & permintaan pasar yang tinggi & \multirow[t]{4}{*}{ kenaikan harga bahan baku } \\
\hline & & $\begin{array}{l}\text { perubahan model dan gaya hidup } \\
\text { masyarakat }\end{array}$ & \\
\hline & & $\begin{array}{l}\text { Dukungan pemerintah dalam } \\
\text { memajukan sektor non migas }\end{array}$ & \\
\hline & & Perkembangan kemajuan teknologi & \\
\hline \multirow{4}{*}{2.} & \multirow{4}{*}{$\begin{array}{l}\text { Lingkungan } \\
\text { Mikro }\end{array}$} & \multirow{4}{*}{$\begin{array}{l}\text { Pasar sasaran yang semakin } \\
\text { berkembang }\end{array}$} & persaingan harga dengan usaha sejenis \\
\hline & & & kekuatan tawar menawar konsumen tinggi \\
\hline & & & kekuatan tawar menawar pemasok tinggi \\
\hline & & & $\begin{array}{l}\text { susah mencaritenaga kerja baru atau } \\
\text { generasi yang terampil }\end{array}$ \\
\hline
\end{tabular}

Pada tabel 3 dapat dilihat bahwa identifikasi peluang dan ancaman didapatkan dari hasil penyebaran kuisioner dari pihak internal yaitu Roman Indah Padang dan pihak eksternal yaitu konsumen dan pesaing.

\section{Analisis Lingkungan Internal (IFE)}

Tabel 4: Matriks IFE Roman Indah UKM Padang

\begin{tabular}{|c|c|c|c|c|c|}
\hline No & $\begin{array}{c}\text { Faktor Internal } \\
\text { Kekuatan (Strength) }\end{array}$ & $\begin{array}{l}\text { Bobot } \\
\text { (1) }\end{array}$ & $\begin{array}{c}\text { Rating } \\
\text { (2) }\end{array}$ & $\begin{array}{l}\text { Skor } \\
(1 \times 2)\end{array}$ & Komentar \\
\hline 1 & $\begin{array}{l}\text { Memiliki sistem manajemen } \\
\text { perusahaan yang baik. }\end{array}$ & 0,078231293 & 3,45 & 0,269897959 & $\begin{array}{l}\text { Dari sisi manajemen, } \\
\text { perusahaan dapat mengelola } \\
\text { seluruh sistem dengan baik }\end{array}$ \\
\hline 2 & $\begin{array}{l}\text { Harga produk yang terjangkau } \\
\text { oleh konsumen }\end{array}$ & 0,079365079 & 3,5 & 0,277777778 & $\begin{array}{l}\text { Dari sisi harga tergolong } \\
\text { murah sehingga dapat } \\
\text { terjangkau oleh konsumen }\end{array}$ \\
\hline 3 & $\begin{array}{lll}\text { Lokasi } & \text { Perusahaan } & \text { yang } \\
\text { strategis } & & \\
\end{array}$ & 0,077097506 & 3,4 & 0,262131519 & $\begin{array}{l}\text { Dekat dengan kampus } \\
\text { maupun lingkungan instansi } \\
\text { pemerintah }\end{array}$ \\
\hline 4 & Modal pribadi perusahaan & 0,066893424 & 2,95 & 0,197335601 & $\begin{array}{l}\text { Sehingga lebih mudah } \\
\text { dalam proses } \\
\text { menjalankan usaha }\end{array}$ \\
\hline
\end{tabular}




\begin{tabular}{|c|c|c|c|c|c|}
\hline 5 & $\begin{array}{l}\text { Produk yang dihasilkan } \\
\text { sangat berkualitas dan tahan } \\
\text { lama }\end{array}$ & 0,080498866 & 3,55 & 0,285770975 & $\begin{array}{l}\text { Produk tersebut dibuat } \\
\text { dengan bahan baku pilihan }\end{array}$ \\
\hline 6 & $\begin{array}{l}\text { Tas dapat dibuat berbagai } \\
\text { model tas sesuai keinginan dan } \\
\text { kebutuhan konsumen }\end{array}$ & 0,066893424 & 2,95 & 0,197335601 & $\begin{array}{l}\text { Karena dikerjakan oleh para } \\
\text { pekerja terampil }\end{array}$ \\
\hline \multirow[t]{2}{*}{7} & $\begin{array}{l}\text { Dikerjakan dengan } \\
\text { menggunakan mesin jahit } \\
\text { modern }\end{array}$ & 0,08276644 & 3,65 & 0,302097506 & \begin{tabular}{|l} 
Untuk \\
tas yanghasilkan karya \\
kualitas bagus
\end{tabular} \\
\hline & Kelemahan (Weakness) & & & & \\
\hline 1 & $\begin{array}{l}\text { Penggunaan website belum } \\
\text { optimal }\end{array}$ & 0,06462585 & 2,85 & 0,184183673 & $\begin{array}{|lrr|}\text { Website } & \text { yang } & \text { dikelola } \\
\text { perusahaan } & \text { masih } & \text { dalam } \\
\text { kategori } & \text { yang } & \text { sederhana } \\
\text { dan } & \text { tidak } & \text { ada } \\
\text { karyawan } & \text { khusus } & \text { untuk } \\
\text { mengelola } & & \text { website } \\
\text { tersebut. } & & \end{array}$ \\
\hline 2 & $\begin{array}{l}\text { Wilayah pemasaran yang } \\
\text { kurang luas }\end{array}$ & 0,062358277 & 2,75 & 0,171485261 & $\begin{array}{l}\text { Segmentasi pasar } \\
\text { dalam masih } \\
\text { pemerintah dan universitas }\end{array}$ \\
\hline 3 & $\begin{array}{l}\text { Belum mempunyai layanan } \\
\text { penjualan melalui internet }\end{array}$ & 0,056689342 & 2,5 & 0,141723356 & $\begin{array}{l}\text { Perusahaan hanya sebatas } \\
\text { melayani penjualan secara } \\
\text { langsung }\end{array}$ \\
\hline 4 & $\begin{array}{l}\text { Proses pembuatan tas memakan } \\
\text { waktu yang cukup lama }\end{array}$ & 0,065759637 & 2,9 & 0,190702948 & $\begin{array}{l}\text { Karena dikerjakan dengan } \\
\text { sangat teliti }\end{array}$ \\
\hline 5 & $\begin{array}{l}\text { Desain produk yang mudah di } \\
\text { tiru oleh pesaing }\end{array}$ & 0,074829932 & 3,3 & 0,246938776 & $\begin{array}{l}\text { Dikarenakan belum } \\
\text { memiliki hak paten } \\
\text { tersendiri }\end{array}$ \\
\hline 6 & $\begin{array}{l}\text { Perusahaan belum memiliki } \\
\text { merek tas }\end{array}$ & 0,078231293 & 3,45 & 0,269897959 & $\begin{array}{|lcr|}\text { Karena } & \text { masih } & \text { dalam } \\
\text { kategori } & \text { Usaha } & \text { Kecil } \\
\text { Menengah } & & \\
\end{array}$ \\
\hline \multirow[t]{2}{*}{7} & Pabrik tas yang kurang luas & 0,065759637 & 2,9 & 0,190702948 & \begin{tabular}{|lrr} 
karena & tempat pengerjaan \\
tas dan & hasil barang yang \\
telah di & produksi & terletak \\
dalam & satu & ruangan \\
sehingga & pabrik & terlihat \\
bertumpuk & &
\end{tabular} \\
\hline & Total & 1 & 44,1 & 3,187981859 & \\
\hline
\end{tabular}

Pada table 4 dapat dilihat nilai skor keseluruhan pada matriks IFE sebesar 3,187981859.

\section{Analisis Lingkungan Eksternal (EFE)}

Tabel 5: Matriks EFE Roman Indah UKM Padang

\begin{tabular}{|c|c|c|c|c|c|}
\hline & Faktor Eksternal & Bobot & Rating & Skor & \\
\hline No & $\begin{array}{l}\text { Peluang } \\
\text { (Opportunities) }\end{array}$ & & & & Komentar \\
\hline 1 & $\begin{array}{l}\text { Permintaan pasar yang } \\
\text { tinggi }\end{array}$ & $\begin{array}{r}0,1134185 \\
3\end{array}$ & 3,55 & $\begin{array}{c}0,40263 \\
5783\end{array}$ & $\begin{array}{l}\text { Dikarenakan adanya acara seminar yang } \\
\text { diadakan oleh } \\
\text { instansi pemerintah dan universitas }\end{array}$ \\
\hline
\end{tabular}




\begin{tabular}{|c|c|c|c|c|c|}
\hline 2 & $\begin{array}{l}\text { Perubahan model dan } \\
\text { gaya } \\
\text { hidup masyarakat }\end{array}$ & $\begin{array}{r}0,0990415 \\
34\end{array}$ & 3,1 & $\begin{array}{c}0,30702 \\
8754\end{array}$ & $\begin{array}{l}\text { Maka, produk tas pun bisa dijadikan } \\
\text { souvenir tidak } \\
\text { hanya sebagai peralatan sekolah }\end{array}$ \\
\hline 3 & $\begin{array}{l}\text { Adanya dukungan } \\
\text { pemerintah } \\
\text { dalam memajukan } \\
\text { sektor non migas }\end{array}$ & $\begin{array}{r}0,0990415 \\
34\end{array}$ & 3,1 & $\begin{array}{c}0,30702 \\
8754\end{array}$ & $\begin{array}{l}\text { Maka, dapat membantu perusahaan dalam } \\
\text { memperluas pasar }\end{array}$ \\
\hline 4 & $\begin{array}{l}\text { Perkembangan kemajuan } \\
\text { teknologi }\end{array}$ & $\begin{array}{r}0,0926517 \\
57\end{array}$ & 2,9 & $\begin{array}{c}0,26869 \\
0096\end{array}$ & $\begin{array}{l}\text { Dengan kemajuan teknologi, produk tas } \\
\text { menjadi lebih } \\
\text { berkembang }\end{array}$ \\
\hline 5 & $\begin{array}{l}\text { Pasar sasaran yang } \\
\text { semakin } \\
\text { berkembang }\end{array}$ & $\begin{array}{r}0,1022364 \\
22\end{array}$ & 3,2 & $\begin{array}{r}0,327156 \\
55\end{array}$ & $\begin{array}{l}\text { Perkembangan mode dalam bidang tas } \\
\text { berdampak pada } \\
\text { perkembangan pasar }\end{array}$ \\
\hline \multicolumn{6}{|c|}{ Ancaman (Threats) } \\
\hline 1 & $\begin{array}{l}\text { Kenaikan harga bahan } \\
\text { baku }\end{array}$ & $\begin{array}{r}0,1054313 \\
1\end{array}$ & 3,3 & $\begin{array}{r}0,347923 \\
323\end{array}$ & $\begin{array}{l}\text { Dapat mempengaruhi faktor penjualan } \\
\text { maupun } \\
\text { pembelian }\end{array}$ \\
\hline 2 & $\begin{array}{l}\text { Persaingan harga dengan } \\
\text { usaha } \\
\text { sejenis }\end{array}$ & $\begin{array}{r}0,1022364 \\
22\end{array}$ & 3,2 & $\begin{array}{r}0,327156 \\
55\end{array}$ & $\begin{array}{l}\text { Dapat berpengaruh terhadap kualitas } \\
\text { produk }\end{array}$ \\
\hline 3 & $\begin{array}{l}\text { Kekuatan tawar menawar } \\
\text { konsumen tinggi }\end{array}$ & $\begin{array}{r} \\
0,0990415 \\
34\end{array}$ & 3,1 & $\begin{array}{r}0,307028 \\
754\end{array}$ & $\begin{array}{l}\text { Kemampuan konsumen untuk menekan } \\
\text { turunnya harga }\end{array}$ \\
\hline 4 & $\begin{array}{l}\text { Kekuatan tawar menawar } \\
\text { pemasok tinggi }\end{array}$ & $\begin{array}{r}0,0958466 \\
45\end{array}$ & 3 & $\begin{array}{r}0,287539 \\
936\end{array}$ & $\begin{array}{l}\text { Pemasok dapat menaikkan atau } \\
\text { menurunkan harga } \\
\text { maupun kualitas barang yang dijual }\end{array}$ \\
\hline 5 & $\begin{array}{l}\text { Susah mencari tenaga } \\
\text { kerja } \\
\text { baru yang terampil }\end{array}$ & $\begin{array}{r}0,0910543 \\
13\end{array}$ & 2,85 & $\begin{array}{r}0,259504 \\
792\end{array}$ & $\begin{array}{l}\text { Dikarenakan pada pekerjaan ini } \\
\text { membutuhkan ketrampilan }\end{array}$ \\
\hline & Total & 1 & 31,3 & \begin{tabular}{|r|}
3,141693 \\
291 \\
\end{tabular} & khusus \\
\hline
\end{tabular}

Pada Tabel 5 dapat dilihat bahwa nilai skor keseluruhan pada matriks IFE sebesar 3,141693291.

\section{Analisis Lingkungan Internal dan Eksternal}

Nilai total skor rata-rata pada matriks IFE sebesar 3,187981859 yang termasuk pada kategori kuat (nilai 3,0 - 4,0) pada baris horizontal. Sedangkan, matriks EFE memperoleh total skor sebesar 3,141693291 yang termasuk pada kategori tinggi (nilai 3,0-4,0) pada baris vertikal. Hasil tersebut menempatkan Roman Indah UKM Padang berada pada sel I yaitu tumbuh dan kembangkan. Strategi intensif (penetrasi pasar, pengembangan pasar, dan pengembangan produk) atau integratif (intregasi ke belakang, intregasi ke depan, dan intregasi horizontal) dapat menjadi paling sesuai untuk divisi-divisi ini, seperti yang dapat dilihat pada gambar 2. Sumbu "kuat" pada garis horizontal untuk matriks IFE dan sumbu "tinggi" pada garis vertikal untuk matriks EFE. Pada posisi ini, dimungkin posisi perusahaan dapat digambarkan sebagai tumbuh dan kembangkan. 
Strategi intregasi ke depan dilakukan perusahaan yaitu mempertahankan eksistensi produk . mempertahankan eksistensi produk ini dapat dilakukan dengan cara mengikuti tren sesuai dengan perubahan zaman dan kemajuan teknologi.

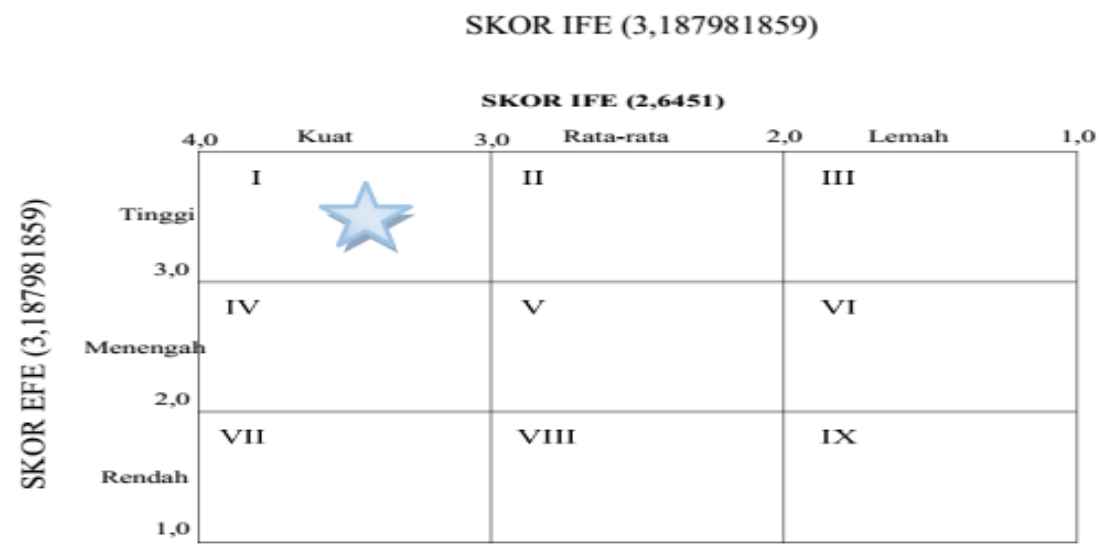

Gambar 2: Matriks IE Roman Indah UKM Padang

\section{Analisis Matriks SWOT}

\section{Tabel 6: Matriks SWOT Roman Indah UKM Padang}

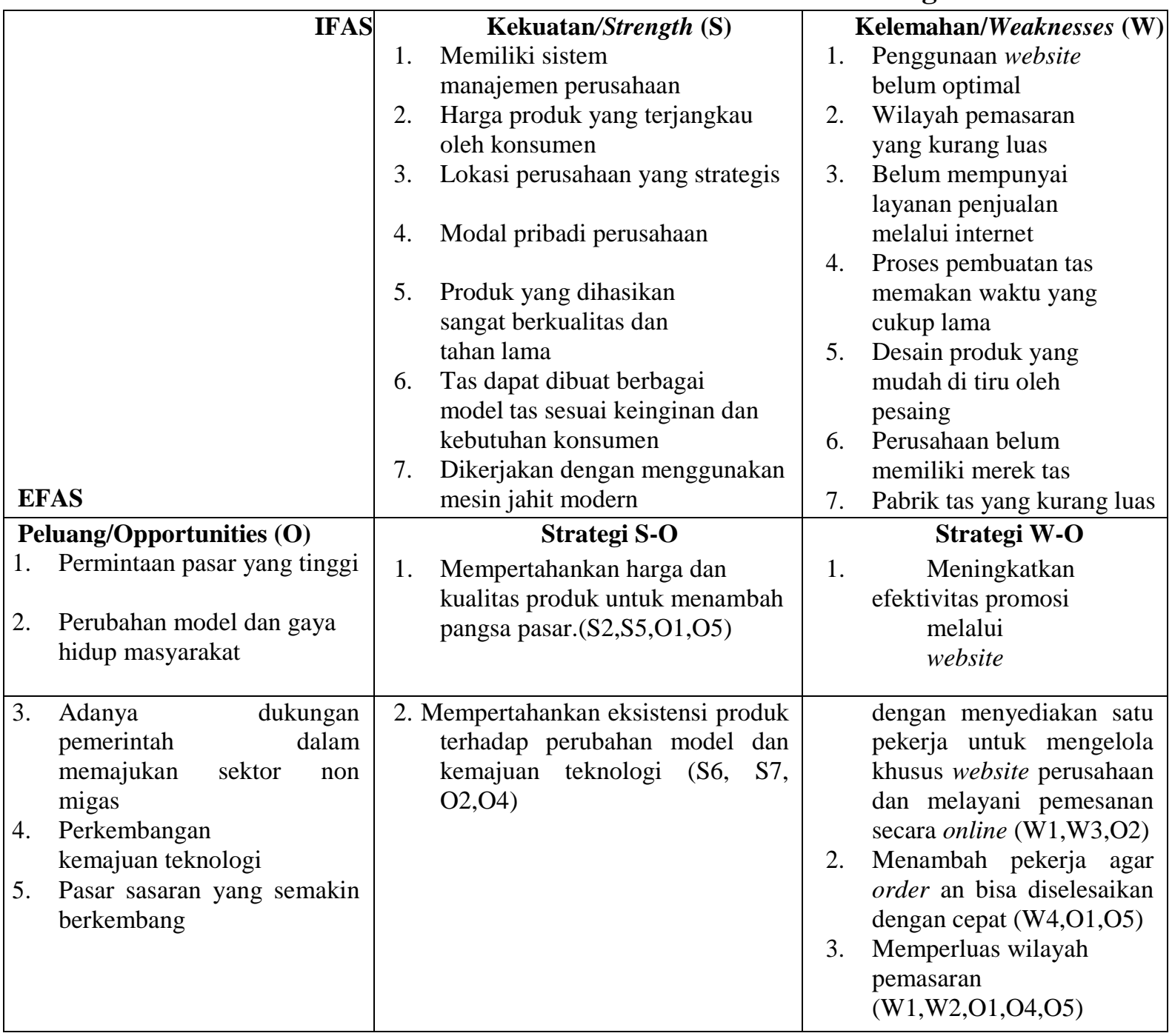




\begin{tabular}{|c|c|c|}
\hline Ancaman/Treath (T) & Strategi S-T & Strategi W-T \\
\hline $\begin{array}{l}\text { 1. Kenaikan harga bahan baku } \\
\text { 2. Persaingan harga dengan } \\
\text { usaha sejenis } \\
\text { 3. Kekuatan tawar } \\
\text { menawar konsumen tinggi } \\
\text { 4. Kekuatan tawar } \\
\text { menawar pemasok tinggi } \\
\text { 5. Susah mencari tenaga } \\
\text { kerja yang terampil }\end{array}$ & $\begin{array}{l}\text { 1. Menetapkan strategi harga pasar } \\
\text { untuk menghadapi persaingan. } \\
\text { (S2, T1,T2, T3,T4) } \\
\text { 2. Menerima mahasiswa dan murid } \\
\text { SMK magang atau PKL untuk } \\
\text { memperoleh tenaga kerja yang } \\
\text { terampil (S6,S7,T5) }\end{array}$ & $\begin{array}{l}\text { 1. Menciptakan produk yang } \\
\text { memiliki ciri khas dan } \\
\text { menciptakan merek produk } \\
\text { agar produk tidak bisa } \\
\text { ditiru oleh pesaing } \\
\text { (W5,W6,T2) }\end{array}$ \\
\hline
\end{tabular}

Dari penyusunan strategi pada matriks SWOT dihasilkan beberapa alternatif strategi antara lain:

1. Mempertahankan harga dan kualitas produk untuk menambah pangsa pasar.(SO-1)

2. Mempertahankan eksistensi produk terhadap perubahan model dan kemajuan teknologi (SO-2)

3. Meningkatkan efektivitas promosi melalui website dengan menyediakan satu pekerja untuk mengelola khusus website perusahaan dan melayani pemesanan secara online (WO$1)$.

4. Menambah pekerja agar order an bisa diselesaikan dengan cepat (WO-2)

5. Memperluas wilayah pemasaran (WO-3)

6. Menetapkan strategi harga pasar untuk menghadapi persaingan (ST-1)

7. Menerima mahasiswa dan murid SMK magang atau PKL untuk memperoleh tenaga kerja yang terampil (ST-2)

8. Menciptakan produk yang memiliki ciri khas dan menciptakan merek produk agar produk tidak bisa ditiru oleh pesaing (WT-1).

\section{KESIMPULAN}

Berdasarkan hasil wawancara dengan pihak responden Roman Indah Padang, strategi pemasaran yang dilakukan saat ini dalam memasarkan produk tasnya yaitu mengembangkan pemasaran setelah memperkuat produksi dan persediaan barang di Padang. dengan hasil QSPM, diperoleh alternatif strategi yang paling sesuai untuk dilakukan yaitu perusahaan bisa menerima mahasiswa dan murid SMK magang atau PKL untuk memperoleh tenaga kerja yang terampil. Maka, dengan strategi yang sudah ada bisa ditambahkan alternatif strategi lain tersebut, sehingga perusahaan bisa lebih meningkatkan produksi dan persediaan. Jadi strategi Roman Indah Padang dapat di pengaruhi oleh alternatif strategi QSPM.

Berdasarkan hasil analisis matrik QSPM, dari delapan alternatif strategi yang ada, terdapat satu alternatif strategi yang diprioritaskan untuk dilakukan oleh perusahaan yaitu menerima mahasiswa dan murid SMK magang atau PKL untuk memperoleh tenaga kerja yang terampil dengan skor TAS sebesar 0,6802 dan hasil ini di dukung oleh jurnal Aris Nugroho dengan judul Analisis Strategi Pemasaran Dengan Menggunakan Metode Quantitative Strategic Planning Matrix (Qspm) Pada Usaha Mebel (Studi Kasus di PT. Wirasindo Santakarya - Wisanka) . 


\section{DAFTAR RUJUKAN}

Aarker, David. 2013. Manajemen Pemasaran Strategis. Edisi 8. Jakarta: Salemba Empat.

Abdullah, Tamrin, Francis Tantri. 2015. Manajemen Pemasaran. Cetakan empat, Edisi1. Jakarta: Rajawali Pers.

Abdurrahman, N.H. 2015. Manajemen Strategi Pemasaran. Bandung: Pustaka Setia.

David, Fred R. 2012. Strategic Management (Manajemen Strategis Konsep). Jakarta: Salemba Empat.

Eli, RP. Purba, C. Kusumadmo, E., 2015. Aanalisis Strategi Pemasaran dengan Menggunakan Metode QSPM (Quantitative Strategic Planning Matrix) di Nimco Indonesia.Jurnal. Universitas Atma Jaya Yogyakarta: Nimco Indonesia.

Mirzakhani, M. Parsamal. E. Golzar, A. 2014. Strategy Formulating With SWOT Matrix: Acase Study An Iranian Company. Payam Noor University. Iran: Iranian Company.

Mulyadi, D. Muslihat, A. Priyanto, A. 2012. Analisis Strategi Pemasaran Jasa Lembaga Pembiayaan Non Bank Pada PT Oto Multiarha Karawang. Jurnal Manajemen Vol.09 No.2. Karawang: Oto Multiarha.

Ningrum, LTW. Diana, WAP. Putri, S.A. 2014. Perencanaan Strategi Pengembangan Menggunakan Metode Quantitative Strategy Planning Matrix (QSPM) (Studi Kasus KUD DAU Malang, Jawa Timur). Jurnal Jawa Timur: KUD DAU Malang.

Nugraha, Agipta Soma. 2011. Strategi Pemasaran Kripik Tempe Pada Industri Rumah Tangga Di Kecamatan Baturetno Kabupaten Wonogiri. Skripsi. Surakarta: Universitas Sebelas Maret.

Nugroho, Aris. 2016. Analisis Strategi Pemasaran Dengan Menggunakan Metode Quantitative Strategic Planing Matrix (QSPM) Pada Usaha Mebel. Jurnal. Santakarya: Wirasindo.

Purwandari, Suci. 2015. Analisis Quantitative Strategic Planning Matrix (QSPM) Sebagai Landasan Menentukan Strategi Pemasaran Pada SMK Citra Medika Sukoharjo. Jurnal Sainstech Politeknik Indonusa Surakarta ISSN : Vol. 1 No. 3. Sukoharjo: SMK Citra Medika.

Rifai, Bachtiar, 2012. Analisis Strategi Pemasaran Usaha Kecil Menengah Pada Usaha Mebel.

Selang, CAD. 2013. Bauran Pemasaran (Marketing Mix) Pengaruhnya terhadap Loyalitas Konsumen Pada Fresh Mark Bahu Mall Manado. Jurnal EMBA Vol.1 No.3. Manado: Universitas Sam Ratulangi.

Suyoto, Danang. 2012. Dasar-dasar Manajemen Pemasaran. Jakarta: CAPS.

Suryatama, Erwin. 2014. Lebih Memahami Analisis SWOT Dalam Bisnis. Surabaya. Kata Pena. 